\title{
O contexto informacional do blog para a disseminação da informação: uma análise teórico
}

\author{
Vanildo Pereira Pontes \\ Universidade Federal do Ceará - UFC, Brasil
}

\section{ANÁLISIS}

\begin{abstract}
Resumo
A ferramenta Blog cresce a cada dia em nossa sociedade sob um contexto dinâmico e interativo, o mesmo surge com a intenção de possibilitar novas formas de usar a escrita para se comunicar e também fazer a divulgação das informações do dia-a-dia. A partir dessas constatações, este artigo propõe fazer uma análise desta ferramenta virtual, no intuito de promover a disseminação e a troca de informações sobre a mesma, que a cada momento está inserida em nosso cotidiano. O processo metodológico foi executado em forma de uma pesquisa qualitativa, cuja apresentação dos itens abordados no trabalho foi pesquisada por fontes de informações especializadas no assunto. O artigo resultou em compreender o blog como uma ferramenta simples; mas apresenta um papel essencial na vida das pessoas, sob informações relevantes na sua compreensão e participação em nossa sociedade.
\end{abstract}

Palavras-chave

Blog ; Disseminação da informação ; Sociedade da informação ; Inclusão digital

The context of the informational blog for dissemination of information: a theoretical analysis

\begin{abstract}
The Blog tool is growing every day in our society with a more dynamic and interactive, it comes with the intention of providing new ways to use writing to communicate and also make the disclosure of day-to-day. From these findings, we propose to analyze this virtual tool in order to promote the dissemination and exchange of information about it, that every moment is embedded in our everyday lives. The methodological process was executed in a form of qualitative research, whose presentation of the items discussed in the paper was searched for sources of specialized information on the subject. The article resulted in understanding the blog as a simple tool, but has an essential role in people's lives, on information relevant to your understanding and participation in our society.
\end{abstract}

Keywords

Blog ; Dissemination of information ; Information society ; Digital inclusion 


\section{Introdução}

A existência de uma organização social denominada sociedade da informação coloca a Internet como a principal responsável pela mudança na forma de como acessarmos, obtermos, organizarmos e usarmos informações para produzir e disseminar conhecimentos. A Internet é um canal pelo qual flui uma grande quantidade de práticas sociais, culturais, políticas e econômicas. A evolução da Web trouxe a criação de espaços cada vez mais interativos, possibilitando que os usuários modifiquem conteúdos e criem novos ambientes hipertextuais. Estes recursos são possíveis devido a uma nova concepção de Internet que está surgindo na era virtual e sendo cada vez mais divulgada e assimilada pelos os usuários, chamada Web 2.0 ou Web Social.

Segundo PRIMO (2007) "A Web 2.0 tem repercussões sociais importantes, que potencializam processos de trabalho coletivo, de troca afetiva, de produção e circulação de informações, de construção social de conhecimento apoiada pela informática".

A Web 2.0 é a segunda geração de serviços on-line e caracteriza-se por potencializar as formas de publicação, compartilhamento e organização de informações, além de ampliar os espaços para a interação entre os participantes do processo. Essa nova concepção de Web engloba todos os recursos que o usuário necessita, promovendo a interação entre os dois (homem e máquina), a qual terá o Blog como ferramenta participativa desta nova revolução no mundo digital, criando espaços cooperativos que o blog possibilitará ao seu usuário. A essência da Web 2.0 junto de suas ferramentas, como o blog, proporcionará uma construção coletiva do conhecimento, onde o usuário junto ao seu conteúdo criará uma conexão para expor e consumir a informação que a sociedade necessita, possibilitando o desenvolvimento das tecnologias de informação em um processo dinâmico e cooperativo.

Este artigo propõe fazer uma análise da ferramenta blog na sociedade da informação, apresentando vários pontos de conhecimento sobre o mesmo. Esses pontos estão relacionados aos conceitos de algumas fontes informacionais que opinam sobre a ferramenta, o seu contexto histórico, a participação do blog na sociedade e outros conteúdos temáticos que o mesmo oferece a comunidade, facilitando o acesso à informação e contribuindo no desenvolvimento racional e intelectual do ser humano na sociedade.

\section{O blog sob a visão de várias fontes informacionais}

O blog ou weblog é o espaço virtual em que são escritos textos, inseridos imagens, idéias e entre outras possibilidades de expor conteúdos informacionais para uso e produção de conhecimento na sociedade.

Para melhor compreensão do que pode ser e para que serve o blog, será apresentado no decorrer deste subtítulo algumas definições pesquisadas. Segundo o dicionário Marketing Terms o termo blog significa "uma publicação freqüente e cronológica de pensamentos pessoais e links da web". Para o portal UOL "Blog é um diário on-line em que você publica histórias, idéias e imagens". Já no sítio Blogger, um dos maiores sítios de criação de blog, encontramos a seguinte definição: "um sítio de fácil utilização, onde você pode postar rapidamente o que pensa, interagir com as pessoas e muitos mais".

No sítio do jornal virtual LE MONDE diplomatique, sobre esta nova forma da escrita e da informação, em uma matéria assinada por Francis Pisani (2003), o autor afirma que "Blog é uma abreviatura de weblog, que se poderia traduzir por diário de bordo da rede" (...). Pisani (2003) acrescenta ainda que:

Os blogs são diários pessoais na internet, mantidos por meios de aplicativos simples que permitem escrever um texto no computador e, desde que esteja conectado, enviá-lo instantaneamente para que seja exibido numa página virtual criada com esse objetivo.

Uma visão parecida é apresentada pela revista Época, onde a mesma publica que, "A definição clássica afirma que é um diário mantido por qualquer um na internet". 
De tudo analisado sobre esse fenômeno informacional, chegamos a uma conclusão de que o blog é uma simples ferramenta, fácil de manusear e um importador de informações no intuito de transmitir o conteúdo para interação social da sociedade.

O blog é estruturado em uma formatação especifica com algumas particularidades, sua estrutura é determinada por um conjunto de blocos de conteúdo textual, imagético ou links que podem ser diariamente atualizados. Para criar um blog o usuário da rede tem a sua disposição softwares específicos (exemplo de software: blogger). Também são adicionadas ferramentas optativas no blog, tais como: permalink - possibilita leitores e escreventes o acesso às mensagens anteriormente postadas; sistema de comentário - permite o leitor interagir com o editor; etc.

Um fator relevante na utilização do espaço público blog é a gratuidade de uso oferecido por grande parte dos sítios.

\subsection{A participação do blog no contexto histórico}

Falar deste fenômeno virtual seria antes de qualquer coisa, contar um pouco do seu contexto histórico em nossa sociedade, pois ao chegar onde se encontra, o blog passou por vários momentos em sua origem e transformação.

O aparecimento do blog só foi possível devido ao intenso processo de transformações políticas, culturais, sociais e tecnológicas experimentadas nas últimas décadas. Entre esse processo de transformação destaca-se a revolução nos meios de comunicação causada pela divulgação rápida de informações, sendo a Internet como o portal de divulgação da informação. O blog como ferramenta de disseminação da informação cria vários tipos de blogs que serão descritos no próximo título.

Segundo Mattoso (2003, p.28) esses diários digitais surgiram na década de 90, quando um simples estudante durante seu horário de lazer, cria uma página virtual que insere textos, para hoje tornar-se uma febre por todas as nações.

Quando o blog teve seu primeiro contato com o usuário, seu conteúdo era criado e editado na rede em código HTML, depois com o surgimento de softwares, ele espalhou-se rapidamente em todo o continente. Em 1999, a empresa americana Pitas lançou um software gratuito para criação de blog e no mesmo ano surgiu o sítio Blogger, tornando-se um fenômeno em criação de blogs. A partir daí o usuário não precisaria ter conhecimentos tecnológicos para criar um blog, pois o software possibilitava passos muito simples na criação e publicação do mesmo.

Desde o princípio de seu surgimento e desenvolvimento, a escalada de crescimento dos blogs não parou. Para exemplificar, o jornal Folha Online, em uma matéria editada no dia 03/01/2005, uma pesquisa divulgada nos Estados Unidos nesta mesma data "mostra que, naquele país, $27 \%$ dos internautas lêem blogs, aumentou de $58 \%$ sobre o ano anterior". O estudo revela também que oito milhões de norte-americanos escreveram em blogs durante o ano de 2004. Isso sem contar os $12 \%$ dos leitores desses diários virtuais que costumam postar comentários nas páginas. Este exemplo demonstra o quanto o blog é importante atualmente à participação na vida das pessoas, sendo um intermediador da informação editada e publicada na vida do homem.

O blog é a ferramenta de comunicação on-line disponível no contexto digital da Internet, representa um fenômeno emergente que vem ganhando a cada dia mais adeptos no mundo inteiro. Grandes empresas de comunicação mundial, como, por exemplo, a BBC de Londres e a Rede Globo, mantêm sítios web que hospedam blogs, tamanho é o interesse que essa ferramenta tem despertado na comunidade de internautas. O termo blog é derivado das palavras inglesas web (rede) e log (diário de bordo). Trata-se de uma abreviatura de web log, em que web representa a rede mundial de computadores e log caracteriza os registros (postings, em inglês) efetuados pelo usuário do blog, o blogger (blogueiro).

A expansão deste novo tipo de interação social está sendo matéria de vários meios de comunicação. Recentemente a revista Época fez uma ampla reportagem intitulada "Blogs - Os campeões de audiência", onde a mesma define "uma linha do tempo com os principais acontecimentos da blogosfera mundial”, a qual será representado pelo gráfico abaixo, onde podemos visualizar todo o processo histórico do blog com seus devidos acontecimentos na história: 


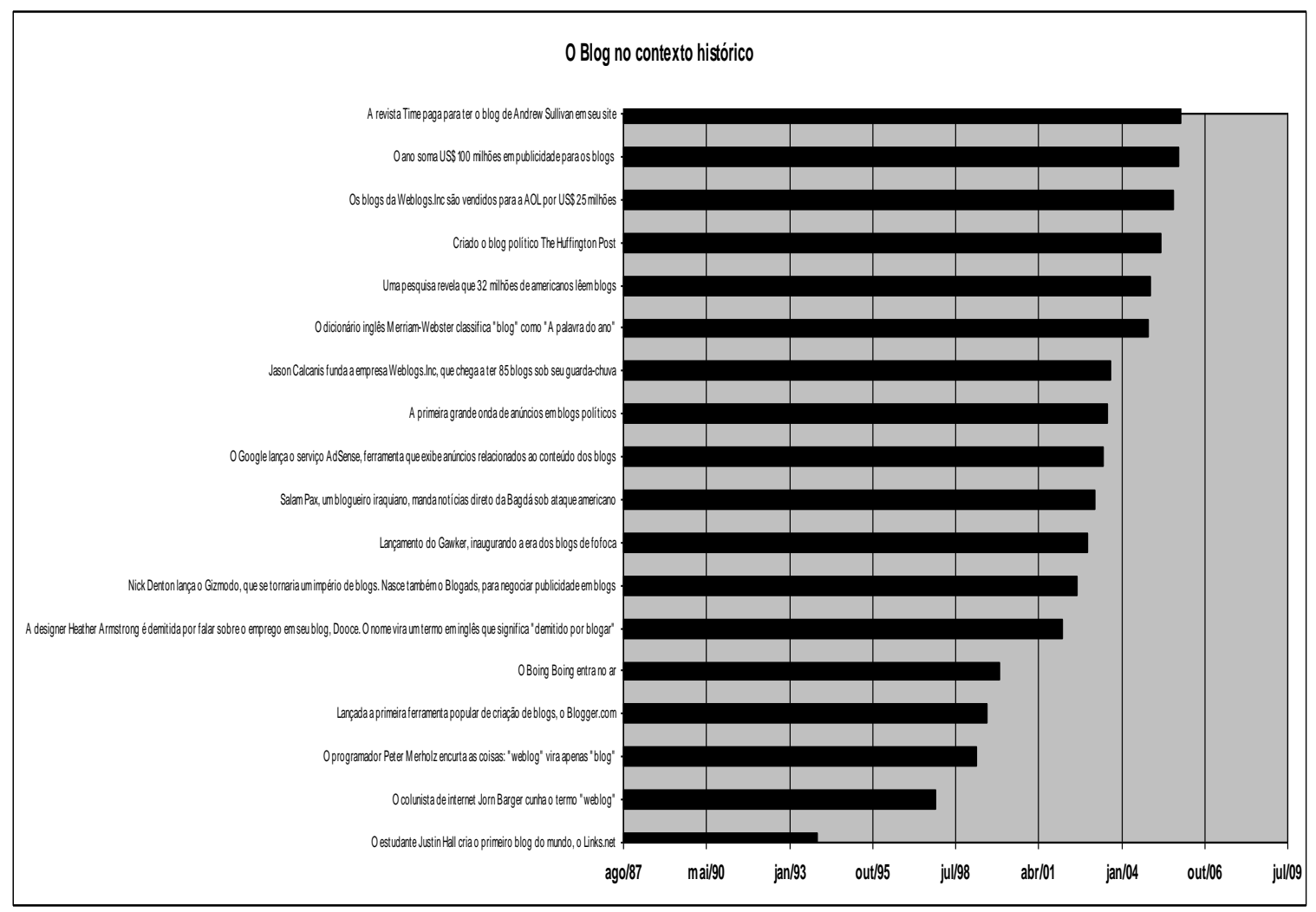

Gráfico 01: Evolução histórica do Blog.

Fonte: dados da pesquisa do contexto histórico.

Diante de todas as informações aqui apresentadas é possível perceber o crescimento deste revolucionário novo meio de comunicação, sendo, portanto, um espaço de comunicação dinâmico e social, como Amorim e Vieira (2006) relatam na revista Época:

Em vez de um meio de comunicação de massa, com um transmissor central para milhões de ouvintes ou telespectadores, a rede mundial promete ser um meio de que todos possam participar, onde todos possam publicar e gerar conteúdo. Promete ser um meio de comunicação não apenas de massa, mas construído pela massa. O que começa tornar essa promessa realidade são os diários virtuais conhecidos como blogs. (AMORIM e VIEIRA, 2006)

A seguir trataremos de forma abrangente as variadas formas de blogs existentes em nosso mundo virtual.

\section{2. $O$ blog sob variadas formas existentes na internet}

Segundo Recuero (2002), devido ás análises feitas por ela no decorrer de sua pesquisa, foi apontado um "semnúmero" de categorias de blogs, sendo que os principais blogs são classificados como:

a) Diários eletrônicos - são os weblogs atualizados com pensamentos, fatos e ocorrências da vida pessoal de cada indivíduo, como diários. Esse blogs são os "diários pessoais", pois os usuários postam suas informações íntimas, no intuito de promover um canal de expressão do autor.

b) Publicações eletrônicas - são weblogs que se destinam principalmente à informação. Eles exibem informações das revistas e jornais eletrônicos, sendo que as notícias, dicas e comentários são sobre determinado assunto. 
c) Publicações mistas - são aquelas que efetivamente misturam posts pessoais sobre a vida do autor e posts informativos, com notícias, dicas e comentários de acordo com o perfil pessoal do usuário.

Enquanto que Oliveira (2003) em sua pesquisa classifica os blogs como pertencentes a três categorias:

- Filtro de notícias - Nesse perfil se enquadram os blogs jornalísticos. O editor desta categoria seleciona, comenta e discute as notícias postadas.

- Filtro temático - São aqueles que captam as notícias de acordo com o assunto. O leitor escolhe o blog baseando-se no seu interesse e gosto pelo tema do mesmo. Nesta categoria podemos enquadrar os blogs corporativos.

- Diários íntimos - Este tipo de escrita é muito parecido com aquela produzida nos tradicionais diários íntimos. O escrevente publica fatos ligados a sua vida íntima particular, sua rotina diária, faz desabafos, revelações diversas.

Portanto todo esse conjunto de blogs espalhados em nosso mundo virtual forma uma "blogosfera" que tem já no seu seio, uma junção de práticas educativas que abarcam uma imensa diversidade de abordagens.

Diante as variadas formas de blogs existentes em nosso espaço virtual, iremos prosseguir com as seguintes temáticas: o blog na sociedade da informação, sua inclusão como ferramenta da tecnologia da informação e comunicação e a nova fase da blogosfera (Microblog ou Nanoblog).

\section{3. $O$ blog na sociedade da informação}

Somos compostos por um sistema sócio, político e econômico em que o conhecimento e a informação constituem fontes fundamentais de bem-estar e produtividade, formando a sociedade da informação. Para o desenvolvimento desta sociedade é necessário impor princípios fundamentais como o respeito aos direitos humanos dentro de seu contexto mais amplo, pois somos formados por setores de vários campos, sendo a educação um direito de todos diante a sociedade.

A sociedade da informação deve ter um viés inclusivo, onde todas as pessoas possam ter a liberdade e as condições para criar, receber, compartilhar e utilizar informações e conhecimentos através da educação. É neste contexto em que o blog torna-se uma ferramenta essencial para a produção, organização e uso da informação no desenvolvimento da comunidade.

A sociedade da informação se apóia no uso intensivo das novas tecnologias, particularmente, as tecnologias da informação e da comunicação, sendo uma forma de organização social moderna, tendo o blog uma rede de comunicação e um recurso de tecnologia de informação altamente desenvolvido, com acesso gratuito e conteúdo apropriado, possibilitando as pessoas alcançarem o seu potencial diante o mecanismo dessas tecnologias associadas ao controle e o domínio da mesma sobre o cotidiano.

A expansão dessas novas tecnologias tem proporcionado à sociedade buscar soluções viáveis para implantar uma infra-estrutura da informação e da comunicação que possibilite o acesso universal, para o progresso social, econômico e bem-estar de todos os cidadãos. E uma dessas soluções viáveis é o blog, pois emerge a participação do usuário em gerar, transmitir, processar, armazenar e recuperar informações de forma eficiente.

Assim, as novas tecnologias da informação e comunicação produzem a representação do conhecimento, voltadas principalmente pra sociedade, tendo a informação como elemento importante para uso e disseminação do mesmo. 


\subsection{Blog: uma ferramenta de inclusão das tecnologias de informação}

Poucas inovações tecnológicas provocaram tantas mudanças em tão pouco tempo na sociedade, entre elas, às novas tecnologias de informação, dentro dessas mudanças está incluído o blog, uma ferramenta revolucionária na sociedade com mudanças de melhoria do conhecimento humano.

O termo informação refere-se aos fatos ou dados, geralmente fornecidos a uma máquina para, com eles, fazer algum tipo de processamento ou operação, tais como: armazenar, transmitir, codificar, comparar, indexar, etc. Em determinados contextos, como na Teoria da Informação, por exemplo, uma mensagem contém informação na proporção em que traz algo novo, até então desconhecido, reduzindo nossa incerteza sobre um determinado estado de coisas. No sentido amplo, toda técnica ou recurso utilizado para realizar alguma operação ou processamento sobre algum tipo de informação, configura uma tecnologia de informação.

Atualmente, é inevitável a associação do termo tecnologia de informação com o blog, essa integração tornou possível o armazenamento da informação sob as mais diversas formas e nos mais diversos meios, tornando acessível pra sociedade.

O desenvolvimento da sociedade depende, hoje, da capacidade de gerar, transmitir, processar, armazenar e recuperar informações de forma eficiente. Por isso, a população precisa ter oportunidades de acesso a esses meios tecnológicos (o blog é um desses meios tecnológicos existentes).

As tecnologias de informação juntamente com o blog, irão favorecer o progresso econômico, político e cultural da humanidade, promovendo a inclusão da informação na sociedade com perspectivas de expandir o conhecimento de forma significativa pra todos.

\subsection{Microblog ou nanoblog: a nova fase da blogosfera}

No final de 2006, a Techonorati estimava existirem cerca de 27 milhões de blogs no planeta. O ritmo de crescimento era de 70 mil por dia. Hoje, a blogosfera deve ter ultrapassado a incrível marca de 50 milhões de blogs. Nunca se escreveu tanto na história da humanidade. Em nenhum outro momento, pessoas tiveram acesso a tantas opiniões e informações escritas. Isso está ocorrendo pela expansão das redes digitais e pelo surgimento de interfaces amigáveis que tornaram viável a transformação em hipertexto da vontade de escrever e de disseminar idéias.

Agora surgem os microblogs ou nanoblogs. Tudo indica que sua utilidade é grande para grupos sociais que precisam estar o tempo todo conectados. Mas o que são nanoblogs?

Microblog ou nanoblog é definido como um pequeno espaço para publicação de breves textos, algo entre 140 e 200 caracteres. Em geral, são escritos para serem vistos por um grupo mais restrito de conhecidos, definidos pelos nanoblogueiros, mas esta prática está em mutação. Os textos curtos podem ser postados por celulares, SMS, mensageiros instantâneos, e-mails ou pela web.

De um lado, o fenômeno pode ser entendido como um reflexo das tendências de espetacularização do cotidiano. De outro lado, pode caracterizar a necessidade de compartilhar experiências e opiniões com mais freqüência.

A seguir iremos explicitar de forma sucinta o processo metodológico do presente artigo.

\subsection{Processo metodológico para o desenvolvimento do artigo}

O blog cresce a cada dia em nossa sociedade e surge com a proposta de possibilitar novas formas de usar a escrita para se comunicar e divulgar as informações do cotidiano. Sua rapidez de expansão é tão intensa que vem causando surpresa até mesmo em especialistas experientes dos meios de comunicação, sendo que, essa ferramenta estar cada vez mais participativa na vida do ser humano, numa perspectiva de integração da informação ao homem em seu contexto diário. O presente artigo foi elaborado de acordo com pesquisas voltadas ao tema (Blog), cujo processo metodológico foi executado em forma de uma pesquisa qualitativa, cuja apresentação dos itens abordados no trabalho foram guiados por fontes de informações especializadas no assunto, tendo por finalidade, a junção de análise informacional que essas fontes definem sobre o tema proposto do artigo. A pesquisa qualitativa deu-se através de múltiplas fontes informacionais relacionados ao assunto, tendo como base em sua elaboração: artigos científicos, livros, revistas, sítios especializados no assunto, etc. Neste artigo, procuramos 
apontar conteúdos de fácil compreensão sobre blog, através de pontos conceituais no assunto abordado e o entendimento das informações atribuídas que essas fontes introduziram no decorrer do trabalho. Assim sendo, o blog como forma de processo conceitual em nossa sociedade, tornou-se um fenômeno de tecnologia da informação e comunicação, pois seus atributos virtuais estão cada vez mais participativos no cotidiano do homem junto às práticas sócio-político-econômico em que está inserido.

\section{Considerações finais}

O presente trabalho resultou compreender o Blog como ferramenta simples que tem um papel essencial na vida das pessoas. Ferramenta esta que pretende promover o uso e a disseminação da informação, para que possa contribuir no desenvolvimento das atividades exercidas pela humanidade, fazendo com que o conhecimento torne-se acessível a todos, num patamar de várias plenitudes do homem com suas atitudes.

O blog vem se configurando como um espaço virtual democrático, que permite dizer, desde os fatos noticiosos dos meios oficiais de comunicação até as banalidades da vida cotidiana das pessoas comuns, sendo um verdadeiro canal de comunicação e divulgação das informações circulares do cotidiano.

Segundo LEVY (1998) "a realidade da influência da tecnologia nos aspectos mais proeminentes de nossas vidas nos obriga a reconhecê-la como um dos temas mais importantes nos debates filosóficos e políticos contemporâneos". Sendo essa afirmação à consagração das novas tecnologias na vida diária do ser humano, efetivando sua participação no contexto dinâmico do mesmo.

Os blogs estão vivenciando a todo o momento as virtudes humanitárias do homem diante suas ações junto à sociedade, sendo que, há várias perguntas sobre essa ferramenta como: o blog como ferramenta de inclusão atingirá todas as classes sociais? Sua contribuição no processo de disseminação da informação será positivo no acesso de seus usuários ao conteúdo consultado? As ferramentas que o blog disponibiliza será de fácil usabilidade por seus usuários? A sociedade em si trará resultados positivos diante esta ferramenta? O blog é uma alternativa para a solução do desenvolvimento da informação em nossa sociedade?

\section{Bibliografía}

AMORIM, Ricardo e VIEIRA, Eduardo (2006). Blogs: os novos campeões de audiência. Revista Época. São Paulo: Globo, n. 428, 15 dezembro 2007. Disponível em:< http://revistaepoca.globo.com/Revista/Epoca/0,,EDG74912-5990-428,00.html >. Acesso em: 18 de maio de 2013.

BLOGGER (2008). 05 janeiro 2008. Disponível em:< http http://www.blogger.com/start >. Acesso em: 18 de maio de 2013.

DICIONÁRIO, Marketing Terms (2008). 10 janeiro 2008. Disponível em:< http://www. marketingterms.com/dictionary/blog/ >. Acesso em: 18 de maio de 2013.

FOLHA ON LINE (2005). Leitura de blogs cresceu 58\% nos EUA em 2004. Folha de São Paulo. São Paulo, 23 dezembro 2007, Disponível em:< http://www1.folha.uol.com.br/folha/informatica/ult124u17773.shtml >. Acesso em: 18 de maio de 2013.

LE MONDE, Diplomatique (2008). 05 jnaiero 2008. Disponível em:< http://diplo.uol.com.br/imprima720 >. Acesso em: 18 de maio de 2013.

LEVY, Pierre (1998). As tecnologias da inteligência: o futuro do pensamento na era da informática. Coleção Trans. Rio de Janeiro: Editora 34.

MANESS, Jack M (2007). Teoria da Biblioteca 2.0: Web 2.0 e suas implicações para as bibliotecas. Informação \& Sociedade: Estudos. João Pessoa, v.17, n. 01, p.44-55.

MAZARGÃO, Augusto (1996). A fadiga de informação. Revista da Comunicação. São Paulo, ano 12, n. 45, p. 20 e 21.

MINISTÉRIO DA CIÊNCIA E TECNOLOGIA (2000). Sociedade da Informação no Brasil. Organizado por Tadao Takahashi. Brasília. 
MATTOSO, Guilherme de Queirós (2003). Internet, jornalismo e weblogs: uma nova alternativa de informação, 20 dezembro 2007. Disponível em:< http://www.bocc.ubi.pt/pag/mattoso-guilherme-webjornalismo.pdf >. Acesso em: 18 de maio de 2013.

OLIVEIRA, R. M. C (2003). De onda em onda: a evolução dos ciberdiários e a simplificação das interfaces. In: Biblioteca on-line de ciências da comunicação. 22 dezembro 2011. Disponível em:< http://www.bocc.ubi.pt/pag/oliveira-rosa-meire-De-onda-onda.pdf >. Acesso em: 18 de maio de 2013.

(2002), Diários públicos, mundos privados: diário íntimo como gênero discursivo e suas transformações na contemporaneidade. 214 f. Dissertação (Mestrado em Comunicação e Cultura Contemporâneas). Universidade Federal da Bahia, Faculdade de Comunicação, Bahia, 22 de maio de 2011. Disponível em: < http://www.bocc.ubi.pt/pag/oliveira-rosa-meire-diariospublicos-mundos-privados.pdf >. Acesso em: 18 de maio de 2013.

PRIMO, Alex (2007). O aspecto relacional das interações na Web 2.0. Revista e-compós. Brasília, v. 9, p. 01-21.

RECUERO, Raquel da Cunha (2002). Weblogs, Webrings, e Comunidades Virtuais. Trabalho apresentado no GT de Comunicação e Cultura do VII Seminário Internacional de Comunicação, 07 de junho de 2011. Disponível em:<

http://www.bocc.ubi.pt/pag/recuero-raquel-weblogs-webrings-comunidades-virtuais.pdf >. Acesso em: 18 de maio de 2013.

(2003). Warblogs: Os blogs, o jornalismo online e a guerra no Iraque. In: XXVII CONGRESSO BRASILEIRO DE CIÊNCIAS DA COMUNICAČÃO, Belo Horizonte. Anais... Belo Horizonte, 07 de junho de 2011. Disponível em:< http://www. bocc.ubi.pt >. Acesso em: 18 de maio de 2013.

(2003). Redes sociais na internet: considerações iniciais. In: XXVII CONGRESSO BRASILEIRO DE CIÊNCIAS DA COMUNICAÇÃO, Belo Horizonte. Anais... Belo Horizonte, 07 de junho de 2011. Disponível em:< http://www. bocc.ubi.pt >. Acesso em: 18 de maio de 2013.

SILVA, Fabiano Couto Corrêa da; BLATTMANN, Ursula (2007). Colaboração e interação na Web 2.0 e biblioteca 2.0. Revista ACB (Florianópolis), v. 12, p. 191-215.

SILVA, Jan Alyne Barbosa (2003). Weblogs: Múltiplas utilizações e um conceito. In: XXVII CONGRESSO BRASILEIRO DE CIÊNCIAS DA COMUNICAÇÃO, Belo Horizonte. Anais... Belo Horizonte, 10 junho 2011. Disponível em:<

http://homer.nuted. edu.ufrgs.br/ObjetosPEAD2006/obj blog/2003 NP08 silva.pdf >. Acesso em: 18 de maio de 2013.

SILVEIRA, Sérgio Amadeu da (2007). Nanoblogs, Twitter e Jaiku: a nova fase da blogosfera. A Rede. São Paulo, n. 32, p. $42-43$.

UOL BLOG (2011). 05 de julho 2011, Disponível em:< http://blog.uol.com.br >. Acesso em: 18 de maio de 2013.

\section{Dados do autor}

\section{Vanildo Pereira Pontes}

Bibliotecário. Possui graduação em Biblioteconomia pela Universidade Federal do Ceará (2010), atuando principalmente nos seguintes temas: biblioteconomia, técnicas biblioteconômicas, automação de bibliotecas e biblioteca escolar.

vanildopontes@hotmail.com

$\begin{array}{ll}\text { Recebido-Received } & : 2013-05-18 \\ \text { Aceito-Accepted } & : 2013-09-27\end{array}$

New articles in this journal are licensed under a Creative Commons Attribution 3.0 United States License.

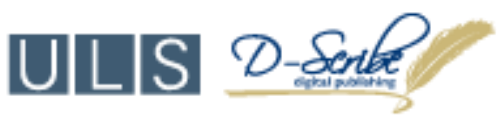

This journal is published by the University Library System of the University of Pittsburgh as part of its D-Scribe Digital Publishing Program and is cosponsored by the University of Pittsburgh Press. 